\title{
La poesía en el periodismo de Antoine de Saint-Exupéry'
}

\author{
Montserrat MORATA SANTOS \\ montsemorata@hotmail.com \\ Universidad Complutense de Madrid
}

Recibido: 2 de julio de 2014

Aceptado: 19 de enero de 2015

\begin{abstract}
Resumen
Entre 1932 y 1938 el escritor y aviador Antoine de Saint-Exupéry colaboró con la prensa francesa de la época, en la que publicó medio centenar de textos. Aunque no fue por vocación por lo que llegó al periodismo, sino por las dificultades económicas que atravesaba en aquel tiempo, sus trabajos en este terreno constituyen una aportación singular y una de las facetas menos conocidas de este autor. Este artículo analiza uno de los rasgos más significativos encontrados en su escritura periodística, como es el uso que hizo de la imagen poética como recurso informativo. Además, a partir de su ejemplo se indaga en los posibles valores compartidos entre el periodismo y la poesía.
\end{abstract}

Palabras clave: Saint-Exupéry, periodismo, poesía, información, imagen poética.

\section{The Poetry in the Journalism of Antoine de Saint-Exupéry}

\begin{abstract}
Between 1932 and 1938 the writer and aviator Antoine de Saint-Exupery collaborated with the French press of his time. These collaborations were a consequence of his economic difficulties as it was not vocation that led him to journalism. However, his work in this field constitutes a singular contribution and one of the lesser known facets about this author. This article analyzes one of the most significant features found in his journalistic writing, since it is the use that he did of the poetic image as an informative resource. In addition, following his example we have looked into the possible common values between journalism and poetry.
\end{abstract}

Keywords: Saint-Exupéry, journalism, poetry, information, poetic image.

\section{Referencia normalizada}

MORATA SANTOS, Montserrat (2015): “La poesía en el periodismo de Antoine de Saint-Exupéry”. Estudios sobre el Mensaje Periodístico. Vol. 21, Núm. 1 (enero-junio), págs.: 131-144. Madrid, Servicio de Publicaciones de la Universidad Complutense.

Sumario: 1. Introducción. 2. Objetivos y metodología. 3. Cuando el hombre de acción se confunde con el periodista y el poeta. 4. En busca de un lenguaje universal. 5. La imagen poética como recurso informativo. Valores compartidos. 6. Conclusiones. 7. Referencias bibliográficas.

\section{Introducción}

Cuando el 25 de mayo de 1939 el periodista Luc Stang preguntó a Antoine de SaintExupéry si se tenía más por escritor o por aviador, éste respondió que no veía tal diferencia. "Para mí volar o escribir son la misma cosa" (Stang, 1971: 219). Esta entrevista, publicada dos días después en Le Figaro Littéraire a raíz del premio que la Academia Francesa acababa de otorgar a Saint-Exupéry por su obra Terre des hom-

1 Este artículo es una síntesis de varios capítulos de la tesis doctoral de la autora (inédita) titulada Acción, pensamiento y poesía en el periodismo de Antoine de Saint-Exupéry. Fue dirigida por el profesor Pedro Sorela Cajiao y defendida en la Facultad de Ciencias de la Información de la Universidad Complutense de Madrid el 7 de noviembre de 2014. 
mes, muestra ya hasta qué punto el vuelo y, en general, la propia vida determinaron su escritura. Una ecuación que se reproducirá en el caso de su periodismo.

Durante los años 30 del siglo XX, y tras haber perdido el oficio de piloto en el que había pasado los mejores años de su vida, Saint-Exupéry vive una agitada época en la que su nostalgia por el vuelo se une a sus problemas personales por el atormentado matrimonio que vivió con la salvadoreña Consuelo Suncín y a las dificultades económicas que atravesaba. En aquel tiempo, para ganar algún dinero, Saint-Exupéry colaboró con la prensa francesa de la época, sin que fuera, ciertamente, la vocación la que le llevó al periodismo. Sin embargo, sus trabajos en este terreno constituyen no sólo una aportación singular, y una de sus facetas menos conocidas, sino que, además, a partir de ellos reescribió después la obra literaria que lo consagró en vida como escritor, y que no fue su famoso Le Petit Prince, cuya gran repercusión no llegaría a conocer, sino Terre des hommes.

En total fueron medio centenar de textos de diversa índole los que Saint-Exupéry publicó entre 1932 y 1938 en algunos de los principales diarios franceses de aquellos años, como los vespertinos Paris-Soir y L'Intransigeant, así como con el semanario político y literario Marianne y, de forma más puntual, en diversas revistas especializadas en aviación y literatura. En muchos casos estos textos nacen de las propias experiencias que el escritor vivió como pionero de la aviación, que se encontraba en sus comienzos, lo que provocó que en ocasiones él mismo protagonizase la actualidad de la que era la gesta de su tiempo. En otros casos, los textos son fruto de los encargos que el autor aceptó para trasladarse como reportero enviado primero a la Unión Soviética de Stalin, en mayo de 1935, por el diario Paris-Soir y, después, a la guerra civil española, en la que estuvo en dos ocasiones. La primera, en agosto de 1936, nada más estallar la contienda, como enviado a Barcelona y el frente de Lérida por L'Intransigeant y al año siguiente en Madrid como reportero de Paris-Soir. Pero también escribió para la prensa otros textos en los que el autor reflexiona sobre cuestiones de actualidad de su época, como diversos acontecimientos vinculados a la aviación, la tensión bélica previa a la Segunda Guerra Mundial o, incluso, de forma más puntual, sobre la civilización industrial nacida del progreso o la nueva idea del viaje que empezaba a gestarse con la llegada de la aviación comercial.

Por tanto, el autor colaboró con la prensa desde diferentes situaciones comunicativas. Pero, en todas ellas, ya fuera la del pionero de la aviación que relata sus experiencias, el que reflexiona sobre acontecimientos de actualidad o la del reportero enviado a algunos de los principales escenarios de su tiempo, se encuentran unos rasgos comunes entre los que destaca la vivencia propia de la que parten sus textos, así como su modo de introducir la poesía en el periodismo.

\section{Objetivos y metodología}

El principal objetivo de este artículo consiste en estudiar una de las principales características de la escritura periodística de Saint-Exupéry, como es el uso que hizo de la imagen poética como recurso informativo. Desde este punto de vista son los textos que escribió tras ser enviado como reportero a escenarios de actualidad lo que más evidencian este rasgo, y por eso este trabajo se centrará en ellos. 
Se trata de un estudio de carácter cualitativo realizado a partir de los textos originales del autor, en este caso recogidos en las Euvres complètes del escritor publicadas en La Pléiade, edición de 1994, en el que también se tendrán en cuenta algunas de las principales ideas propias sobre la escritura que el aviador desarrolló en toda su obra. Además, a partir del ejemplo de Saint-Exupéry se indagará en los posibles valores compartidos entre el periodismo y la poesía.

De ahí que este artículo aspire no sólo a aportar un estudio original de la obra periodística del escritor francés sino también a introducir nuevos puntos de vista sobre la búsqueda de nuevas fórmulas de expresión en el periodismo que, además de una actividad profesional, "también es un arte porque todo lo que se fabrica con herramientas simbólicas puede serlo. Es más, debe tender a serlo" (Casals, 2005: 552).

En cuanto a las traducciones de las citas del francés al castellano, han sido utilizadas las que existen en las Obras completas de Saint-Exupéry editadas por Plaza \& Janés en 1974, reseñadas en la bibliografía, así como algunas de las realizadas por Eva Aladro sobre las series de reportajes "Espagne ensanglantée" y "Madrid". En el resto de los casos las traducciones corresponden a la propia investigadora.

\section{Cuando el hombre de acción se confunde con el periodista y el poeta}

Si en Saint-Exupéry no puede separarse al escritor del aviador esta misma situación se reproduce en su periodismo, que no sólo parte de sus propias experiencias sino que también estuvo determinado por su forma de entender la escritura como consecuencia de la propia acción. Según señala Pedro Sorela, que ha desarrollado la idea de que en Saint-Exupéry escritura y vida vienen a ser lo mismo, el escritor francés, aunque sólo vivió 44 años, tuvo una vida tan intensa "que uno se pregunta si Stendhal no estaría pensando en él cuando propuso la idea de que es preciso hacer de la propia vida una obra maestra como condición para escribirla" (Sorela, 2006: 349).

Además, Saint-Exupéry decía que "no hay que aprender a escribir sino a ver" (Saint-Exupéry, 1994a [Vol. I]: 787), lo que constituye otra idea central de su pensamiento que desarrollará en toda su obra. En términos no sólo literarios sino también periodísticos esto supone que es la mirada, es decir, la forma de asomarse a la realidad, lo que determina la reconstrucción que, en última instancia, se hace de ella.

Ante esta primera premisa cabe preguntarse, en primer lugar, dónde se sitúa y qué tiene de particular la mirada de Saint-Exupéry. La respuesta, teniendo en cuenta su condición de piloto y su afán constante por volar, resulta ser también una consecuencia: con frecuencia en las alturas, es decir, por encima de la realidad convencional y en un medio distinto. Durante el tiempo que trabajó como piloto volaba dos días de cada tres y, según su amigo el doctor Georges Pélissier (1951: 54), llegó a acumular una experiencia de 7.000 horas de vuelo. De hecho, en su obra son recurrentes los elementos naturales, a los que se enfrentó, como la noche, las estrellas, la tormenta, las nubes o la tierra vista desde las alturas, imágenes a partir de las que construye numerosas analogías.

De esta forma, el hombre de acción en Saint-Exupéry es un hacedor, un creador en definitiva, que adquiere el conocimiento no por la inteligencia racional ni desde la condición de mero testigo, sino por la experiencia y participación directa, haciendo así del acto la propia obra. 
Según esta idea se puede considerar que Saint-Exupéry es un poeta en el sentido etimológico de la palabra, que procede del griego poietés y que se refiere a "quien hace o crea", lo que constituye, según recuerda el poeta Joan Margarit, "un significado muy anterior a la propia escritura" (Margarit, 2009: 47). Por extensión también puede decirse que la poesía sería esencialmente creación, una creación que no sólo antecede a la palabra escrita sino que la trasciende. Además, en la propia idea de creación estaría implícita la de transformación que se encuentra ya formulada en una de las grandes obras de la antigüedad, como las Metamorfosis de Ovidio. "Mi inspiración me lleva a hablar de las figuras transformadas en cuerpos nuevos: dioses, sed favorables a mis proyectos, pues vosotros mismos ocasionasteis también esas transformaciones" (Ovidio, 2012: 24), dice el poeta en su proemio.

En el caso de la obra periodística de Saint-Exupéry, no sólo fue hacedor y creador, a través de sus propias experiencias, de algunas de las historias que después relató para la prensa, sino que incluso él mismo fue en ocasiones protagonista de la actualidad como pionero de la aviación. El caso más destacado fue el de su accidente en el desierto libio, que casi le costó la vida, cuando trataba de batir el récord París-Saigón, un acontecimiento que ocupó durante la primera semana de 1936 las portadas de los periódicos franceses de la época y que después el propio aviador relató, en primera persona, en L'Intransigeant.

Por otra parte, para Saint-Exupéry, que consideraba al hombre básicamente como "nudo de relaciones", una idea esencial de su pensamiento, la aviación era un oficio que daba sentido a su vida, ya que lo ponía en contacto con los hombres y le permitía generar lazos entre ellos a través del correo que entonces transportaba. De ahí también la importancia que Saint-Exupéry daba a la responsabilidad, "ser hombre significa ser responsable" (1974: 221) dice en Terre des hommes, por lo que consideraba que para ser hombre, y no individuo, era necesario participar. "Tu acto eres tú" (1973: 138), señala en Pilote de guerre un autor que anteponía el espíritu a la inteligencia como forma de conocimiento.

Pero Saint-Exupéry fue también un científico que dejó registradas trece patentes para mejorar la aviación de su tiempo y que, en ocasiones, recurre a las leyes de la física para hacer poesía. Admiraba a Newton porque, en su opinión, lo que hizo no fue descubrir una ley disimulada como quien resuelve un acertijo, sino que realizó una operación creadora. "Fundó un lenguaje de hombre que pudiera expresar a la vez la caída de una manzana en un prado o la ascensión del sol. La verdad no es lo que se demuestra. Es lo que simplifica" (Saint-Exupéry, 1974: 326).

El escritor francés conectaría así con un pensamiento según el cual tras las cosas más sencillas y esenciales de la naturaleza se esconderían sus grandes secretos universales a la espera de ser descubiertos, es decir, vistos. "Conocer no es desmontar ni explicar. Es acceder a la visión. Mas para ver conviene antes participar" (Saint-Exupéry, 1973: 45). Para ello el escritor creía que era necesario un instrumento. En su caso eligió el avión, no como un fin sino como un medio a través del que medirse con las fuerzas naturales y extraerles nuevos significados, según desarrolla en Terre des hommes, donde, ya en sus primeras líneas, expone este pensamiento. "La tierra nos enseña más sobre nosotros mismos que todos los libros. Porque se nos resiste. El hom- 
bre se descubre a sí mismo cuando se mide con el obstáculo. Pero para alcanzarlo le hace falta un instrumento" (Saint-Exupéry, 1994a [Vol. I]: 171)².

A su vez, durante el vuelo el piloto es un pensador que puede abstraerse y, en medio del silencio y la soledad, realizar una reflexión que no nace de la contemplación sino del acto que lleva a cabo. De esta forma, para el aviador, el "poema perfecto sería un 'acto', una reencarnación del verbo" (François, 1957: 197-198).

Además, según André Maurois, "el aviador difiere del resto de los hombres de acción porque su mundo es singularmente abstracto. La tierra, vista desde las alturas, se vacía. De cada diez horas, el avión vuela nueve sobre mares, desiertos o selvas" (Maurois, 1947: 140). Por eso cree que cuando Saint-Exupéry utiliza imágenes que para los demás resultan poéticas, para el piloto serían la descripción "simple y verdadera de lo que contempla" (Ibíd.: 141).

Esta idea lleva a considerar, a la hora de analizar el uso que Saint-Exupéry hizo en sus textos periodísticos de abundantes imágenes poéticas ${ }^{3}$, que tal vez para él no lo fueran sino que se correspondían con la realidad desde su particular punto de vista. "Si hubiese imaginación del ojo, como la hay del avión, el ojo nacería porque la conciencia es creadora" (Saint-Exupéry, 1974: 1507), dice en una de las anotaciones de sus Carnets ${ }^{4}$.

De acuerdo con estas ideas se puede considerar, respondiendo a la pregunta que se formulaba al principio de este epígrafe sobre cómo es la mirada de Saint-Exupéry, que su mirada es poética, es decir, creadora, a partir de su propia acción, en su caso, a través del avión como instrumento.

\section{En busca de un lenguaje universal}

El lenguaje fue una de las principales preocupaciones de Saint-Exupéry, precisamente porque también lo fue llegar a comunicarse y ser comprendido, lo que está relacionado con su creencia en la necesidad de crear lazos entre los hombres. No obstante, pensaba que el lenguaje racional era insuficiente para trasladar las cuestiones esenciales de la vida. De ahí que buscase un lenguaje que, como la música, pudiera ser descifrado no por la razón sino por el espíritu. De hecho la música tuvo una gran influencia tanto en su formación, a través de su madre, como en el resto de su vida. Podía pasarse noches enteras escribiendo mientras escuchaba, una y otra vez, por ejemplo, el Bolero de Ravel.

Además, el escritor pensaba que cuando una sociedad evoluciona ya no se puede seguir reflejando la realidad mediante un lenguaje caduco y defendía que la verdadera libertad residía en la creación. "Ese lenguaje insuficiente es el que se hace, poco a poco, contradictorio: nunca las realidades. El hombre se libera solamente cuando forja un nuevo concepto" (Saint-Exupéry, 1994a [Vol. I]: 346), señala en uno de sus

2 Traducción de Pedro Sorela (2006: 364).

${ }^{3}$ La imagen poética es definida por Angelo Marchese y Joaquín Forradellas como "la introducción de un segundo sentido, ya no literal, sino analógico, simbólico, 'metafórico' en un trozo de texto". (1986: 206).

${ }^{4}$ Recogen las anotaciones que a partir de 1935 realizó Saint-Exupéry en la libreta de piel que siempre llevaba encima y en la que apuntaba ideas y reflexiones sobre temas diversos. 
artículos de la serie "La Paix ou la guerre?", publicada en los primeros días de octubre de 1938 en el diario Paris-Soir.

También creía que toda disciplina, artística o científica, no es otra cosa que lenguaje, que el lenguaje lo es todo (Delange, 1948: 136). "Comprendió bien que el hombre -ante todo- es un lenguaje, el más agudo de los problemas" (Saint-Exupéry, 1994a [Vol. I]: 319), concluye en su texto "Escales de Patagonie", publicado el 30 de noviembre de 1932 en el semanario Marianne y en el que relata algunas de sus experiencias al frente de la Aeropostal Argentina.

Este pensamiento conecta con su idea de que el espíritu trasciende a la inteligencia. De ahí que rechazase el lenguaje racional como verdadero medio de conocimiento y comunicación de la realidad más allá de su apariencia, y que considerase eficaz sólo el lenguaje que revelase lo inexpresado, aspirando a extraer del error una parte de verdad.

En su búsqueda de ese lenguaje universal el escritor recurrió con frecuencia al uso de la imagen poética. Pero también perseguía la claridad y empleaba un lenguaje sencillo, era un poeta, aunque no lo parece, ya que las palabras que utiliza no están predispuestas de antemano para la poesía sino que se convierten a ella por la transposición de imágenes de la realidad que connotan sus campos semánticos. Según Luc Stang (1971: 222), "el lenguaje que tanto preocupa a Saint-Exupéry no se reduce a un vocabulario más o menos rico. Las palabras son signos y tiene menos importancia añadir unos signos a otros que aumentar su significado". Para el escritor Daniel Anet el carácter de poeta del aviador se manifiesta tanto "en su afán por evitar el peligro de una imagen usada" como en el empleo que hace del lenguaje como "los signos del álgebra". "Él tiende a excluir todo aquello que no signifique" (Anet, 1946: 45-46).

Además, persigue hacerlo con la sencillez del que aspira a comunicarse. Según recuerda Pedro Sorela, decía que "la primera cualidad de un hombre inteligente es comprender el lenguaje de los otros y hablarles en él" (2006: 429).

El resultado es una escritura sencilla pero a la vez profunda, densa en pensamiento y de aparente claridad. Para alcanzar esta escritura esencial, el aviador, además de realizar una escrupulosa selección del lenguaje, escribía primero de largo y después corregía una y otra vez sus textos, restaba y condensaba hasta reducirlos a una tercera o cuarta parte de lo que había escrito, quitando más que dejaba, un proceso que puede rastrearse en Citadelle, la obra póstuma que dejó sin pulir. "Yo no sé escribir, yo sólo sé corregir" (Saint-Exupéry, 1999 [Vol. II]: 969), le decía en una carta a su amiga Nelly de Vogüé un autor que formula su ideal de escritura en Terre des hommes cuando dice que "la perfección no se consigue cuando no hay nada más que sumar sino cuando no hay nada más que restar" (Saint-Exupéry, 1974: 225).

Junto a ello, aspiraba a que este proceso no se notase, para lo que ponía un cuidado especial en el ritmo, y empleaba imágenes cuyas dimensiones fuesen accesibles para la imaginación del hombre, que toma como medida y en torno al que gira su pensamiento, lo que también trasladó a sus textos periodísticos.

\section{La imagen poética como recurso informativo. Valores compartidos.}

Uno de los rasgos más característicos de la escritura periodística de Saint-Exupéry es que introduce la poesía en textos que no están predispuestos para ello. Lo hace cre- 
ando una atmósfera en la que tiende a sugerir más que a describir, así como recurriendo con frecuencia al uso de la imagen poética. Lo singular, en su caso, es que utiliza este recurso al margen de la situación comunicativa desde la que escribiera incluida la de reportero-, así como de la función que tuviera el texto. Esto supone que el escritor traslada la poesía al periodismo no sólo en aquellos textos que podrían considerarse de opinión, o en los que relata algunas de sus vivencias en la aviación, sino también en los que tenían una finalidad informativa, aunque fuera con amplias dosis de interpretación. Es el caso de los que escribió tras ser envidado a escenarios de máxima actualidad e interés por los principales diarios franceses de su tiempo, como Paris-Soir y L'Intransigeant, que los publicaron como "grandes reportajes" dedicándoles un amplio espacio en portada. Desde este punto de vista son estos textos los que más evidencian, y por eso este estudio se centra en ellos, no sólo la ruptura que SaintExupéry hace de la clásica división entre información y opinión, sino que también pueden tomarse como ejemplo de las posibilidades informativas de la poesía. De ahí también la originalidad periodística de este autor, que sustituye literalidad por creación para representar la realidad que observa, en la que participa y sobre la que reflexiona desde su propia mirada y experiencia.

El escritor pensaba que "la verdad no se descubre, se crea" y que tampoco reside en el texto, "sino en la topografía del texto" (Saint-Exupéry, 1974: 1491), según dice en las anotaciones de sus Carnets. "Cuando se trata de expresar relaciones entre elementos que yo enuncio y sobre los que no puedo actuar, la expresión de estas relaciones ya no es una observación sino un acto creador puro" (Ibídem).

Este acto creador, que parte de su propia acción, lleva a Saint-Exupéry a establecer nuevas relaciones entre elementos dispares para alumbrar una realidad que se oculta a simple vista. De este modo lo ordinario se convierte en extraordinario, es decir, adquiere interés, un camino en el que se cruzarían tanto el periodismo como la poesía, disciplinas ambas que si algo tendrían en común es el valor de alumbrar lo nuevo. Cierto es, no obstante, que en el caso del periodismo la novedad se fundamenta con frecuencia en la realidad medible y cambiante, es decir, en su apariencia, y que para ello se utilizan fórmulas establecidas a partir de las que se supone que el informador toma distancia para mostrar una realidad lo menos intervenida posible. Sin embargo, estos ideales en ocasiones se han vuelto contra el propio periodismo ya que, como es sabido, desde el cumplimiento de sus propias reglas también pueden ocultarse mayores dosis de realidad de las que se muestran.

Pero, además, si entendemos que el periodismo tiene como principal misión "ensanchar los círculos de la realidad" (Casals, 2005: 206) y que el periodista es, en definitiva, "un narrador de realidades" (Ibíd.: 248), también se puede afirmar que lo contrario al periodismo sería, precisamente, todo lo que oculta o esconde la realidad que se aspira a mostrar. No sólo de un modo explícito o intencionado, sino también a través de la ausencia de significación tanto del contenido como del lenguaje empleado. Es aquí donde se encontraría otro valor compartido entre la poesía y el periodismo, en este caso por lo que, en esencia, no son: lugar común. "Un tópico no es un pensamiento sino su cáscara", dice Pedro Sorela (2012: 37) en su novela y ensayo El sol como disfraz, donde uno de sus personajes "describía el tópico como el 'censor más 
peligroso', superior a los partidos políticos o la publicidad, pues más aún que ellos 'el tópico llena los ojos de niebla sin que éstos se den cuenta: el sueño mismo de un tirano" (Ibíd.: 176).

En el caso de Saint-Exupéry uno de sus principales propósitos era comunicarse y ser comprendido, pero también llegar a decir, para lo que aumenta el significado de las palabras mediante el uso de imágenes poéticas con las que extraer de la realidad una verdad más profunda que su apariencia. Para ello crea analogías, es decir, imágenes que son poéticas precisamente por su novedad, justo lo contrario al lugar común.

Sobre la creación de estas imágenes, el autor decía en sus Carnets que si asociaba dos nociones que no tenían entre sí una relación evidente -y que poseían, no obstante, alguna posibilidad de intercomunicación-, su espíritu tendía a situarse "en un universo en el que esta relación arbitraria es válida" (Saint-Exupéry, 1974: 1498). "La lógica no tiene agarradero para explicar esta creación. Ésta empieza precisamente donde termina la lógica", que "es impotente para explicar la imagen. Y más aún para proponerla" (Ibíd.: 1499). Decía, además, que el valor de la imagen sólo tenía una garantía: su eficacia. "Creo en la verdad de la poesía (...). El poeta no es más fútil que el físico. Uno y otro recortan verdades" (Ibíd.: 1500).

También "recortar" y mostrar una parte de la realidad sería, en esencia, un valor propio del periodismo, en el que, como en el resto de su obra, Saint-Exupéry busca encontrar, a través de su propia observación, esa realidad que no se ve a primera vista. "Todo inventor es en principio un observador" y Saint-Exupéry "era un observador infatigable" (Pélissier, 1951: 187).

De esta idea puede extraerse otro cruce de caminos entre el periodismo y la poesía, ya que ambas disciplinas parten de observar, buscar y encontrar, aspirando después a trasladar el propio hallazgo con la mayor precisión y exactitud posible. En ese proceso, entre la observación y el descubrimiento se produce una interrelación entre distintos elementos que puede hacerse mediante la abstracción poética o, también, en el periodismo, estableciendo nuevas relaciones entre los hechos que dan lugar a una realidad cambiante que adquiere interés.

En el caso de Saint-Exupéry, lo que busca, según Luc Stang, es que "por medio del lenguaje haya una invención en sí, creación de pensamiento por la creación literaria que se manifiesta mediante el descubrimiento de nuevas relaciones entre las palabras y las cosas que evocan" (Stang, 1971: 222). De este modo, aspira a devolver al lenguaje un valor significante que considera que no puede encontrarse en las fórmulas desgastadas. No se trata, por tanto, de utilizar la poesía como ornamento, sino como un instrumento mediante el que mostrar realidades que permanecían ocultas porque carecían de un lenguaje que las hiciera visibles y comunicables. De ahí que en su periodismo Saint-Exupéry no utilice la imagen poética como un recurso únicamente valorativo, sino también interpretativo e informativo, para dar cuenta de la realidad que observa. Para ello, lejos de tomar distancia o aparentar objetividad -un valor periodístico que ya existía en su tiempo pese a la habitual toma de partido de la prensa-, escribe sus textos en primera persona, a partir de su vivencia, trasladando al lector su propia mirada sobre la realidad, que no es descriptiva sino poética. Y lo mismo que en sus obras introduce la poesía en realidades aparentemente tan contrarias a ella como la mecánica, en su 
periodismo lo hace para hablar de la revolución o de la guerra. Así ocurre, por ejemplo, en el primer texto que escribió tras ser enviado por L'Intransigeant a la guerra civil española, dentro de la serie "Espagne ensanglantée", cuando el reportero llega a Cataluña pilotando el avión del periódico y busca en el paisaje, a través de la imagen poética, la frontera invisible de la guerra. También en sus reportajes sobre Madrid, publicados en Paris-Soir, se refiere a los bombardeos que sufre la ciudad con la siguiente imagen: "El golpe resuena sobre el yunque: un herrero gigante forja Madrid" (SaintExupéry, 1994a [Vol. I]: 412), o, en su serie sobre Moscú habla de la opresión de Stalin como de "esa mano de hierro que pesaba sobre la ciudad" (1974: 1148). Otro ejemplo de cómo Saint-Exupéry recurre a la imagen poética para informar de una realidad se encontraría en el relato que hace de uno de los ataques que vivió, durante la guerra civil española, en las trincheras de Carabanchel, junto a los milicianos:

"Ahora aquí, en el fondo de esta bodega, oíamos cómo se deshacía nuestro navío. Algo se desmembraba lentamente. La luna entraba por las fisuras. Nos oponíamos a esta invasión de lo impalpable. De la luna, de la noche, del mar. De vez en cuando la tempestad rompe y sus golpes de ariete nos estremecen [...] ¿Están atacando ellos? ¡Parece un maleficio! A través de aquella tronera nada pude ver, seguro, nada más que una estrella. Y ahora el ametrallador suelta ráfagas. Cuando dispara la estrella parece temblar en el agua. La noche compone sortilegios, luchamos contra las estrellas..." (Saint-Exupéry, 1994a [Vol. I]: 414).

En este pasaje se puede observar que el punto de vista del aviador, aún desde la tierra, parece buscar el cielo. También aparecen elementos naturales recurrentes en su escritura, como las estrellas, la noche o el mar, en este caso, desde la analogía que establece entre las trincheras y un navío. Se trata también de algo habitual en SaintExupéry, la construcción de analogías entre el mar y el cielo, el avión y el barco o, incluso, en ocasiones, entre el piloto y el buzo, para lo que adopta el punto de vista de su propia experiencia, un rasgo común en su escritura. "Debemos escribir, pero con el propio cuerpo" (Saint-Exupéry, 1994b: 97), le dijo en una ocasión a la periodista norteamericana Dorothy Thompson cuando ésta le reprochó los riesgos que asumía para seguir volando durante la Segunda Guerra Mundial.

A partir de este punto de vista el autor fija su mirada en detalles que hace visibles y que se convierten en símbolo de la realidad que relata en sus textos. Para ello, su mirada reproduce operaciones que podría decirse que también guardan alguna relación no sólo con el vuelo sino también con las operaciones derivadas de éste, como el despegue, con el que se amplía la perspectiva por elevación o alejamiento, y el aterrizaje, con el que se acerca. En su primer reportaje de la serie "Espagne ensanglantée", por ejemplo, Saint-Exupéry busca la frontera de la guerra cuando sobrevuela España y no la encuentra, hasta que, ya en Barcelona, presencia en la terraza de un café la detención de un hombre que se llevan a fusilar. Pero el reportero no dice explícitamente que lo vayan a matar, sino que lo sugiere a través de un detalle que se convierte en símbolo de la muerte, en este caso, un vaso medio lleno que el hombre había dejado encima de la mesa, "el último de su vida" (Saint-Exupéry, 1994a [Vol. I]: 392). A continuación relata que cuando este hombre se pone en camino "sus dos manos levantadas por encima de la cabeza parecían las de un hombre que se está ahogando". 
"Y yo veía alejarse, cernidos los riñones por carabinas, a aquél por el que, a dos pasos de mí, cinco minutos antes, pasaba la invisible frontera" (Ibídem). Tras posar su atención en el vaso la mirada del reportero podría decirse que despega, es decir, se aleja y cobra altura hasta construir la imagen del hombre que se ahoga y encontrar en él la "frontera invisible" de la guerra que había buscado al sobrevolar la ciudad.

Otro ejemplo de estas operaciones se encontraría en el pasaje del ataque vivido en las trincheras de Carabanchel citado anteriormente. En este texto, titulado "La guerre sur le front de Carabanchel", dentro de la serie de "Madrid", publicada en Paris-Soir, también se daría una progresión entre los distintos enfoques mencionados. Desde los parapetos el campo de batalla es un mar negro, las trincheras son un barco en medio de la tempestad y el combate se libra entre las estrellas. "Allí abajo nos mezclamos con la extraña vida submarina. Rozo, sin conocerla, a esta población tragada por la tierra" (Ibid.: 413). A continuación su mirada se detendrá en un detalle concreto para, después, volver a alejarse y tomar altura. En concreto, Saint-Exupéry cuenta que los combatientes junto a los que se encuentra habían recibido la orden de atacar a la mañana siguiente. Durante esa noche vive junto a los milicianos los momentos previos al ataque y habla de su propia agitación, ya que iba a acompañarlos en el asalto, así como de una muerte a la que no le ve sentido. En esta vigilia angustiosa, Saint-Exupéry centra su punto de vista en un elemento que adquiere un valor simbólico: un despertador. Los soldados "prosiguen mientras sea posible esa partida de ajedrez. Hacen que la vida dure mientras puedan. Sin embargo, un viejo despertador atruena sobre una repisa. Lo han puesto para que les avise. Yo soy el único que lo mira a hurtadillas. ¿Cómo es que nadie lo oye? ¡Hace un ruido ensordecedor!” (Ibíd.: 416). Cuando suene ese despertador, relata, estos hombres se incorporarán y, "sin apresurarse demasiado, tomarán prestado ese corredor" hasta el cielo, "dirán alguna cosa simple, como "bonito claro de luna' o 'hace bueno'. Y se lanzarán a las estrellas" (Ibídem).

Se trata de algunos ejemplos de los muchos similares que pueden encontrarse en los textos periodísticos de Saint-Exupéry, que construye sus imágenes poéticas a partir de su particular punto de vista, determinado por su propia experiencia como aviador, en la que se enfrentó a las fuerzas naturales. El avión era para él un instrumento de conocimiento que en este caso trasladaría también al lenguaje, el instrumento propio del periodista. Pero, incluso, las preguntas que el autor se formula en cada escenario están determinadas por una mirada propia. Al llegar a Moscú, por ejemplo, el reportero se pregunta dónde está la revolución, igual que lo hace después en España por la guerra y, más allá de la evidencia, lo que busca no son los hechos aislados sino su consecuencia, su señal en la tierra o en los hombres con los que se encuentra. Para descubrir esta huella recurre con frecuencia a la creación de analogías entre la acción humana y los elementos naturales. Así, cuando se refiere a los ataques que vive junto a los milicianos en las trincheras de Carabanchel dice que allí "al hombre se le acomete lentamente, como a un árbol" (Saint-Exupéry, 1994a [Vol. I]: 414). En otro texto de la misma serie sobre Madrid la historia del "sargento R...", que decidió a ir a la guerra tras la muerte de un amigo, le recuerda al mismo impulso que se produce en los patos cuando ven pasar a las aves en la época de las migraciones. "La llamada salvaje ha tocado en ellos [...] Y entonces los patos de las granjas se convierten por un minuto 
en pájaros migratorios [...] se les desarrollan las extensiones continentales, el gusto por los vientos de altura y la geografía de los mares" (Ibíd.: 421).

El reportero recurrirá de nuevo a los pájaros, sugiriendo una analogía con sus propios vuelos, para hablar en el mismo texto de cómo se enfrentan los soldados a un combate en el que estaban dispuestos a dejarse la vida. "Hay partidas en los pájaros migratorios que se emprenden con viento contrario sobre el océano. Y el océano se hace demasiado largo para su vuelo, no saben si llegarán a la otra orilla. Pero en sus pequeñas cabezas está la imagen del sol y de la cálida arena sosteniendo el vuelo" (Ibíd.: 422).

Los elementos naturales que el escritor conoce por su condición de piloto, así como los animales que tanto le gustaban, y que tienen una presencia llamativa tanto en su vida como en su obra -baste recordar el famoso zorro del desierto de Le Petit Princesirven habitualmente a Saint-Exupéry para crear analogías con las que profundizar en el comportamiento humano. "En el desierto se siente el transcurrir del tiempo [...] Bajo la quemadura del sol, animales y hombres, con idéntica seguridad que lo hacen hacia la muerte, avanzan hacia ese gran abrevadero. Así, la ociosidad nunca es vana. Y cada jornada parece hermosa, como esos caminos que conducen al mar" (SaintExupéry, 1974: 264), dice en el texto titulado "Bark, esclave maure", publicado el 17 de mayo de 1933 en el semanario Marianne, en el que relata algunas de sus experiencias durante el tiempo que pasó en Cabo Juby, la actual Tarfaya marroquí, como comandante en jefe de la base que allí tenía la Aeropostal.

Pero el autor no sólo recurre a la construcción de analogías entre el comportamiento humano y la naturaleza sino que el proceso también se produce a la inversa, estableciendo así una constante vinculación entre el hombre y la tierra, pero también entre lo concreto y lo abstracto. De ahí que otro recurso al que recurre en su escritura sea la figura de la prosopopeya o personificación, consistente en "atribuir a un ser inanimado o abstracto cualidades típicas de los seres humanos. Si el ser personificado se convierte en emisor del mensaje se produce la prosopopeya; si en destinatario, el apóstrofe" (Marchese / Forradellas, 1986: 318).

Así, en los reportajes de Cataluña describe la guerra como una enfermedad, mientras que en las trincheras de Carabanchel la muerte adquiere rasgos humanos, como la noche. "Una vaina madura explota en algún sitio. De vez en cuando, absurda, una bala chasquea así contra la piedra. Es la muerte que vaga, sin duda, pero desocupada, sin mala intención" (Saint-Exupéry, 1994a [Vol. I]: 418). Otro ejemplo se encontraría en el texto que escribió, dentro de la serie de "La Paix ou la guerre?", recordando algunas de sus vivencias en las trincheras de Carabanchel, donde le llamó la atención que, en el silencio de la noche, los combatientes de uno y otro bando se llamaran por sus nombres y se respondieran. "La noche entera canta, como una concha" (Ibíd.: $352)$.

De esta forma también acerca lo abstracto a la dimensión humana, que toma como medida. Para "hacer sentir" Saint-Exupéry creía que a veces había que reducir las proporciones de lo que se contaba con el fin de que fuesen asequibles para la imaginación del lector. Y es lo que lo hace con la guerra o con la muerte en la batalla. Jacques de Dampierre (citado en Sorela, 2006: 437) contaba que el escritor le explicó en alguna ocasión el problema de "hacer sentir" del siguiente modo: 
“Coja por ejemplo un hombre en una barca. Una ola enorme se lo va a tragar. ¿Estará más asustado por un rodillo de treinta o de cien metros que por uno de diez? Incluso si el abismo real es de treinta metros, y si lo escribo con honestidad, el lector no me creerá, o al menos no lo sentirá. Perderemos el contacto. Hace falta medir en función del hombre".

De esta forma, en lugar de hacer una descripción literal Saint-Exupéry opta por mostrar estas realidades a través de imágenes poéticas accesibles para el lector, ya sea creando analogías o personificando elementos tanto naturales como abstractos. Además, estos recursos, la analogía y la prosopopeya, simbolizan lo que son los dos temas esenciales de sus textos, el hombre y la tierra, que aparecen vinculados.

Resulta llamativo también que junto al uso de prosopopeyas Saint-Exupéry utilice el recurso contrario, estableciendo animalizaciones, es decir, analogías entre animales e individuos para ahondar en el comportamiento humano ante ciertas situaciones como la guerra, con lo que tiende a sugerir más que a describir. Así, por ejemplo, en uno de los reportajes de la serie "Espagne ensanglantée" dice que el comportamiento de los hombres que temen ser fusilados por los anarquistas le recuerda a "esos pobres monos que bailan delante de la boa para enternecerla" (Saint-Exupéry, 1994a [Vol. I]: 400). También en las trincheras de Carabanchel los milicianos se asemejan, ante los ataques, a "esos peces que se pescan con un anzuelo de hierro, hurgando en los agujeros" (Ibíd.: 413).

A través de estos recursos, además, no sólo se manifiesta la mirada propia y el pensamiento humanista del escritor sino que se funde con la poesía. De ahí que las figuras que en este caso Saint-Exupéry emplea no tengan una función decorativa sino propiamente informativa, dirigida a acercar al lector la realidad que el reportero observa en primera persona, cierto que interpretada e, incluso, puede decirse que valorada, ya que hay una carga moral implícita que responde al propio pensamiento del autor.

Además, la imagen poética constituía para él un recurso más completo que la palabra desnuda. Desconfiaba de los razonamientos y buscaba una renovación del lenguaje como instrumento de conocimiento y representación de la realidad, que aspiraba a trasladar con la precisión y simplificación del físico que realiza una operación creadora para explicar el mundo. "Necesitamos que nos hablen en un lenguaje sencillo para que podamos entenderlo" (Saint-Exupéry, 1974: 201), dice en Terre des hommes, y de ahí que las imágenes que emplea sean construidas con palabras que no están predispuestas para la poesía, así como a través de la naturaleza, cuyos elementos son reconocibles y universales.

Junto a ello, su búsqueda de un nuevo lenguaje tiene que ver con su constante afán por comunicarse y ser comprendido. Si el escritor ve al hombre como "nudo de relaciones", desde esta misma concepción creía que el lenguaje es, precisamente, lo que anuda. "Nada de lo que concierne al hombre puede contarse, nada puede medirse. La verdadera extensión no existe para el ojo, sólo se acuerda con el espíritu. Vale lo que vale el lenguaje, pues el lenguaje es lo que anuda las cosas" (Saint-Exupéry, 1973: 87). De ahí que buscase un "lenguaje universal" que le permitiera crear lazos de unión entre los hombres, que fuera descifrado por el espíritu en lugar de la inteligencia. Este lenguaje se correspondería con la imagen poética si tenemos en cuenta que su recep- 
ción, que pasa por la imaginación en lugar de la razón, hace partícipe al lector del proceso creativo en la representación compartida que se hace de la realidad.

De esta forma Saint-Exupéry introduce la creación no sólo en contextos no predispuestos para ello, sino también en una actividad como el periodismo que, en su caso, se confunde con la poesía. Se establece así, a través de su ejemplo, una función informativa en la poesía y un vínculo con el periodismo a partir de algunos de los valores que ambas disciplinas comparten.

\section{Conclusiones}

En la escritura periodística de Saint-Exupéry la acción se confunde con la poesía a partir de su propia vivencia y su particular mirada sobre la realidad, derivada en muchos casos de su condición de aviador. Además, desde su propia experiencia y observación el autor establece nuevas relaciones entre las cosas, formando un pensamiento propio que transmite, con frecuencia, a través del uso de la imagen poética. A la vez, a partir de su propio punto de vista como aviador, que le aporta un conocimiento distinto de la realidad, el escritor va de lo particular a lo universal, así como de lo abstracto a lo concreto. Crea imágenes con las que interrelaciona elementos diferentes, que resultan reconocibles y a los que otorga nuevos significados. De ahí que pueda decirse que la poesía en Saint-Exupéry sería el resultado de combinar la abstracción creadora con la precisión del conocimiento que le aporta su propia experiencia, situándose, para sugerir, entre la mirada que ve y la mirada que imagina.

El uso de la imagen poética se convierte así en un medio de conocimiento y en un recurso para informar de cuestiones que, aun teniendo que ver con algo más que los hechos aparentemente objetivos, atañen a los hombres y forman parte de la realidad sobre la que el periodismo aspira a dar cuenta. Igual que en Saint-Exupéry el avión es un instrumento de indagación en su escritura periodística lo sería el lenguaje y, en particular, su dimensión poética derivada de la propia acción. Además, en la concepción del lenguaje de Saint-Exupéry se encuentra también su carácter humanista, ya que a través de él persigue la creación de lazos y, en su aspiración de comunicarse y ser comprendido, recurre a la creación de imágenes poéticas que, como la música, puedan ser descifradas por la imaginación y la abstracción, cualidades propias de los hombres.

Como en el resto de su obra, también en sus trabajos periodísticos aspira a devolver al lenguaje un valor significante que consideraba que no podía encontrarse en fórmulas desgastadas. De ahí también la función informativa que, en su caso, tiene la poesía, cuyos recursos ofrecen al periodismo la posibilidad de llegar a esa parte de la realidad que pasa desapercibida, que va más allá de los hechos, pero que es tan real como éstos. La poesía se convierte así en un instrumento periodístico mediante el que mostrar realidades que permanecían ocultas porque carecían de un lenguaje que las hiciera visibles.

Se establece así un vínculo entre el periodismo y la poesía que va más allá del uso que tradicionalmente se ha hecho de ella en el periodismo de opinión y que pone el enfoque precisamente en sus posibilidades informativas, estudiadas a partir del ejemplo de Saint-Exupéry. En este caso, a partir de los valores compartidos entre el perio- 
dismo y la poesía, cuyos recursos pueden contribuir tanto a mejorar la expresividad del lenguaje como a profundizar en la realidad sobre la que informar.

De ahí también el interés que, aun partiendo del pasado, tiene la obra periodística de Saint-Exupéry a la hora de ofrecer nuevos cauces de reflexión ante los retos que se plantean para el periodismo escrito e impreso de nuestro tiempo que, precisamente en la actualidad, se encuentra en un proceso de transición y de búsqueda de nuevas fórmulas que le permitan seguir aportando elementos diferenciales.

\section{Referencias bibliográficas}

ANET, Daniel (1946): Antoine de Saint-Exupéry. Poète-Romancier-Moraliste. Paris, Éditions Corrêa.

CASALS, María Jesús (2005): Periodismo y sentido de la realidad. Teoría y análisis de la narrativa periodística. Madrid, Editorial Fragua.

DELANGE, René (1948): La vie de Saint-Exupéry. París, Éditions du Senil.

FRANÇOIS, Carlo (1957): L'Esthétique d'Antoine de Saint-Exupéry. París, Delachaux \& Niestlé.

MARCHESE, Angelo y FORRADELLAS, Joaquín (1986): Diccionario de retórica, crítica y terminología literaria. Barcelona, Editorial Ariel.

MARGARIT, Joan (2009): Nuevas cartas a un joven poeta. Barcelona, Barril Barral editores.

MAUROIS, André (1947): Creadores de mundos. Barcelona, José Janés Editor.

OVIDIO (2012): Metamorfosis. Madrid, Ediciones Cátedra.

PÉLISSIER, Georges (1951): Les cinq visages de Saint-Exupéry. Paris, Flammarion.

SAINT-EXUPÉRY, Antoine de (1973): Piloto de guerra. Barcelona, Círculo de Lectores.

SAINT-EXUPÉRY, Antoine de (1974): Obras completas. Barcelona, Plaza \& Janés, Editores.

SAINT-EXUPÉRY, Antoine de (1994a): Euvres complètes. [Vol. I]. Paris, Éditions Gallimard. Bibliothèque de La Pléiade.

SAINT-EXUPÉRY, Antoine de (1994b): Écrits de guerre. 1939-1944. Paris, Éditions Gallimard.

SAINT-EXUPÉRY, Antoine de (1999): OEuvres complètes. [Vol. II]. Paris, Éditions Gallimard. Bibliothèque de La Pléiade.

SORELA, Pedro (2006): Dibujando la tormenta. Faulkner, Borges, Stendhal, Shakespeare, Saint-Exupéry. Inventores de la escritura moderna. Madrid, Alianza Editorial.

SORELA, Pedro (2012): El sol como disfraz. Madrid, Alfaguara.

STANG, Luc (1971): Saint-Exupéry visto por sí mismo. Madrid, Editorial Magisterio Español. 